Vol. 10 (1): 87-98 (2020)

\title{
NANOAGROCHEMICALS: ECOTOXICOLOGICAL RISK ASSESSMENT
}

\author{
Valeria Bondar $^{1 *}$, Natalia Makarenko ${ }^{1}$, Volodymyr Makarenko², Lyudmyla Symochko ${ }^{3}$ \\ ${ }^{1 * N a t i o n a l ~ U n i v e r s i t y ~ o f ~ L i f e ~ a n d ~ E n v i r o n m e n t a l ~ S c i e n c e s ~ o f ~ U k r a i n e, ~ H e r o i v ~ O b o r o n y ~ S t r e e t, ~ 15, ~ 03041 ~ K y i v, ~}$ \\ Ukraine; \\ ${ }^{2}$ Kyiv Taras Shevchenko National University of Kyiv, Volodymyrska Street, 64/13, 01601, Kyiv, Ukraine; \\ ${ }^{3}$ Uzhhorod National University, Voloshyna Street. 32, 88000, Uzhhorod, Ukraine;
}

*Corresponding author Valeria Bondar, e-mail address: lera_bond@email.ua;

Received November 2019; Accepted December 2019; Published January 2020;

DOI: https://doi.org/10.31407/ijees10.113

\begin{abstract}
In the agricultural sphere, a large number of nanopreparations with insecticidal, herbicidal, fungicidal action is used to increase plant immunity to adverse environmental factors and to improve their mineral nutrition conditions. At the same time, a large amount of data on the environmental hazards of nanoproducts has been accumulated: active migration into the environment, phytotoxicity, negative impact on soil, aquatic, terrestrial ecosystems. The toxic properties of nanoparticles depend, first of all, on the presence of nanoparticles smaller than $100 \mathrm{~nm}$ in their composition. Therefore, a new scientific direction - nanoecotoxicology - has been actively formed recently. One of the tasks of this direction is development of methods for researching the environmental hazard of nanomaterials. The purpose of our research was to study environmental risks and to establish safety standards for the use of plant growth nanoregulators. Electron scanning and biotest methods were used (effective inhibitory action on soil $\mathrm{N}-$ mineralization and ecotoxicity using Allium test). It was found that in the system of nanotoxicology scanning electron microscopy method is expedient to use to determine the size, qualitative, quantitative composition, and structure of nanoparticles, which allows making assumptions about the toxicity of the nanoparticle. Biotesting methods were proposed for quantitative risk characterization and determination of safe nanoparticle application rates.
\end{abstract}

Keywords: biotest, ecotoxicology, nanotechnology, nanoagrochemicals 